\title{
Minerva Diaz de Sá Barreto e o Atendimento às Pessoas com Deficiência em Barbalha-CE
}

\author{
Minerva Diaz de Sá Barreto and Assistance to People with Disabilities in Barbalha-CE
}

\author{
Tania Maria Rodrigues Lopes ${ }^{\mathrm{a}}$; Francisca Genifer Andrade de Sousa ${ }^{\mathrm{a}}$, Lia Machado Fiuza Fialho*a
}

aniversidade Estadual do Ceará. CE, Brasil.

*E-mail: lia_fialho@yahoo.com.br

\begin{abstract}
Resumo
$\mathrm{O}$ estuda trata do atendimento às pessoas em situação de vulnerabilidade da cidade de Barbalha-CE, mais especificamente das crianças com deficiência intermediado por uma americana residente no Brasil. Objetiva-se biografar Minerva Diaz de Sá Barreto, fundadora da Associação Pestalozzi, com ênfase no seu envolvimento com as práticas caritativas e de assistência social que fomentaram atendimento às pessoas com deficiência da cidade de Barbalha-CE (1964-2010). Utilizou-se a metodologia da história oral, com a realização entrevistas livres e individuais com oito mulheres que conviveram com a biografada na referida instituição. As narrativas oralizadas foram gravadas, transcritas, textualizadas e validadas, consolidando-se em fontes orais documentadas. Reconstituiu-se a vida de Minerva Barreto desvelando as particularidades da trajetória de uma americana que foi morar no interior do Ceará, ao casar-se com um cidadão da região do Cariri, após lograr de formação educacional diferenciada. Averiguou-se que, em Barbalha, Minerva Barreto se empenhou em assistir às pessoas empobrecidas por meio de práticas caritativas e assistenciais, desde o desenvolvimento de projetos para a garantia da sobrevivência a promoção da inclusão às crianças com deficiência com a criação de instituições para atende-las, sendo a fundação da Associação Pestalozzi um dos seus maiores feitos. Concluise que o seu reconhecimento social e sua atuação junto às crianças com deficiência foi possível graças ao capital cultural adquirido fora do Brasil, a sua sensibilização pessoal e a condição de esposa do prefeito da cidade.
\end{abstract}

Palavras-chave: Biografia. Minerva Diaz. Associação Pestalozzi. Assistência social.

\begin{abstract}
The study deals with the care of people in situations of vulnerability in the city of Barbalha-CE, more specifically of children with disabilities mediated by an American resident in Brazil. The aim is to biograph Minerva Diaz de Sá Barreto, founder of the Pestalozzi Association, with an emphasis on her involvement with charitable and social assistance practices that fostered care for people with disabilities in the city of Barbalha-CE (1964-2010). The oral history methodology was used, with free and individual interviews with 08 women who lived with the biography in that institution. The oralized narratives were recorded, transcribed, textualized and validated, consolidated in documented oral sources. Minerva Barreto's life was reconstructed, revealing the particularities of the trajectory of an American woman who went to live in the interior of Ceará, when she married a citizen of the Cariri region, after achieving a differentiated educational background. It was found that, in Barbalha, Minerva Barreto endeavored to assist impoverished people through charitable and assistance practices, from the development of projects to guarantee survival to the promotion of inclusion for children with disabilities with the creation of institutions to assist them, the foundation of the Pestalozzi Association being one of its greatest achievements. We conclude that her social recognition and her work with children with disabilities was made possible by the cultural capital acquired outside Brazil, her personal awareness and the condition of wife of the mayor of the city.
\end{abstract}

Keywords: Biography. Minerva Diaz. Pestalozzi Association. Social assistance.

\section{Introdução}

A escrita biográfica considera as experiências vivenciadas pelo sujeito em um determinado contexto na sua interface com a conjuntura social na qual está inserido (DOSSE, 2015), por conseguinte, cada pessoa, seja ela anônima ou não, importa na constituição da historiografia, pois, na perspectiva teórica da história cultural (BURKE, 2008), todos os indivíduos são sujeitos históricos. Todavia, a biografia, ao entrelaçar-se à hermenêutica, indica a indissociabilidade entre o individual e o coletivo (LEVI, 2016), possibilitando reduzir a escala de análise e lançar lume a singularidades e individualidades não abarcadas em pesquisas macrohistóricas (LORIGA, 2011).

Nessa perspectiva, questiona-se: como uma mulher de nacionalidade americana, ao chegar à Barbalha, cidade interiorana da região Nordeste marcada pela precariedade de recursos públicos, conseguiu se tornar referência no trabalho com a assistência social e fundar a Associação Pestalozzi, primeira instituição da região a atender pessoas com deficiência? Em congruência, objetiva-se biografar Minerva Diaz de Sá Barreto, fundadora da Associação Pestalozzi, com ênfase no seu envolvimento com as práticas caritativas e de assistência social que fomentaram atendimento às pessoas com deficiência da cidade de Barbalha-CE (1964-2010). Considerou-se aspectos familiares, educativos, sociais, culturais, políticos e econômicos, com foco na sua trajetória de luta pela inclusão social, no combate à vulnerabilidade, bem como pelo atendimento especializado às pessoas com 
deficiência residentes em Barbalha, localizada ao Sul do Ceará.

Dessa feita, o estudo enfatiza o protagonismo e o pioneirismo de Minerva Diaz de Sá Barreto, doravante apenas Minerva, uma mulher considerada revolucionária pelo povo barbalhense por ter dedicado grande parte de sua vida aos menos abastados economicamente, adotando para si a luta por atendimento às pessoas com deficiência na perspectiva de incluí-las. Interessa inferir que essa atuação se deu majoritariamente na segunda metade do século XX, em meio a um contexto histórico marcado por abandono, esquecimento e rejeição das pessoas com deficiência, tanto por parte das famílias como da sociedade e dos governantes; o que mantinha o deficiente relegado a segundo plano de importância na definição de políticas de inclusão (SOUSA; NASCIMENTO, 2018). Posto que a delimitação temporal do estudo, 1964 a 2010, indica a chegada de Minerva à Barbalha, mais especificamente quando deu início aos serviços prestados às pessoas com deficiência, e, respectivamente, o ano do seu falecimento, quando encerra seu trabalho.

Minerva Diaz nasceu nos Estados Unidos, onde iniciou e concluiu a sua escolarização no ínterim da primeira metade do século XX. Estudou a Educação Básica $^{1}$ e o Ensino Superior em instituições privadas, demonstrando pertencer a uma família de considerável poder econômico. No Brasil, conquanto, o acesso à educação formal pelo público feminino era diminuto, pois difundia-se o entendimento de que as mulheres poderiam ser instruídas no próprio lar, seguindo o exemplo das mães, já que não precisam de níveis elevados de escolarização para galgar um bom casamento e atuar na condição de donas de casa (MAGALHÃES JUNIOR, 2003). $\mathrm{Na}$ contramão dos paradigmas culturais brasileiros, Minerva, ao fixar residência no país, mais precisamente na zona rural do município de Barbalha, tornou nítido o contraste àquela população no que concerne ao grau de formação, já que, não somente naquela região, mas em outras cidades interioranas do país, a lenta propagação dos grupos escolares, situados nos centros urbanos, inviabilizava para muitos o acesso à educação daqueles que habitavam áreas mais afastadas (ARAÚJO, 2015).

Minerva, chegou ao Brasil para realizar trabalho voluntário a serviço dos Estados Unidos no interior do Nordeste brasileiro e se mostrou solícita às causas daquela população negligenciada pelo poder público. Destacou-se pela sua atuação junto as famílias em situação de vulnerabilidade social, em especial no atendimento para pessoas com deficiência, ofício que se dedicou até falecer, aos 73 anos de idade. Inclusive, interessa destacar que a instituição de maior visibilidade social, a Associação Pestalozzi, pioneira no atendimento especializado em Barbalha, foi onde Minerva galgou certa visibilidade, por coordenar seus primeiros anos de funcionamento e ter enfrentado um panorama de adversidades decorrentes do diminuto recurso para manutenção do estabelecimento.

Importa destacar que se procurou por produções acadêmicas prévias com os descritores "Minerva Diaz de Sá Barreto", no campo "assunto", no banco de teses e dissertações da Coordenadoria de Aperfeiçoamento de Pessoal de Nível Superior (Capes), onde não se encontrou nenhum trabalho; fato idêntico ocorreu na busca realizada com o descritor “Associação Pestalozzi". Também foi consultada a Scientific Electronic Library Online (SciELO) na busca por artigo e o portal de periódicos da Capes, no campo "buscar assunto", com os mesmos descritores - "Minerva Diaz de Sá Barreto" e "Associação Pestalozzi", inseridos um a um, e nada foi encontrado. Tal ausência de estudos sobre as Associações Pestalozzi e sobre Minerva, ensejam originalidade, bem como certo ineditismo a pesquisa em tela.

$\mathrm{O}$ estudo permitiu reconstituir a história de Minerva, mulher que revolucionou a prática assistencial à população carente de Barbalha, pois, mesmo na escassez de investimento público, fundou a Associação Pestalozzi com vistas a proporcionar o desenvolvimento das pessoas com deficiência, e investiu na formação dos profissionais que ali atuavam. Sua relevância consiste na preservação da história e memória de Zuíla no imbricamento com a Pestalozzi de Barbalha, o que enseja reflexão e problematização sobre a história de mulheres, pouco protagonizadas nos escritos da historiografia (PERROT, 2017), e os mecanismos de enfrentamento ao parco interesse do Estado em suprir atendimento às pessoas com deficiência.

A discussão sobre a história de vida de Minerva, objeto de estudo da pesquisa, na interface com aspectos educativos, familiares, sociais, econômicos e profissionais foi realizada a partir de quatro sessões: 1) "Introdução", que detevese a apresentar brevemente a temática, sua delimitação, o problema de pesquisa, o objetivo do estudo, a relevância da investigação e sua estrutura textual; 2) "Material e Métodos", que explanou, com amparo teórico, o percurso desenvolvido para a realização da pesquisa; 3) "Resultado e Discussão", na qual se elaborou a narrativa biográfica de Minerva, discutindose desde a sua escolarização até o Ensino Superior, bem como sobre a sua visita ao Brasil e a mudança de residência para essa pátria. Salientou-se também as ações de inclusão social e combate à vulnerabilidade na periferia Barbalhense com a fundação da Fundação da Associação Pestalozzi de Barbalha; e, por fim, 4) "Conclusão", nas quais se retoma o problema e objetivo da pesquisa para respondê-los sucintamente.

1 Interessa salientar que a Educação Básica nos Estados Unidos se estrutura de maneira diferente se comparada ao Brasil: "Day Caree preschool equivalem à educação infantil; kindergarten faz parte da elementary school e destina-se acrianças entre 5 e 6 anos; middle school, para alunos com idade entre 11 e 13 anos; e high school tem duração de quatro anos" (ABU-EL-HAJ, FIALHO, 2019, p. 24). No entanto, nesse estudo, utilizzaram-se as terminologias brasileiras para facilitar a compreensão leitora no Brasil. 


\section{Material e Métodos}

O estudo, de natureza qualitativa, ampara-se nos ensinamentos da História Cultural (BURKE, 2008), a partir da qual foi alargada a compreensão de fonte histórica considerando todo vestígio do homem no tempo como fonte historiográfica. Nessa abordagem, os estudos na área das Ciências Humanas foram realçados e deu-se início ao estudo do tempo presente com vistas a investigar e problematizar o desenvolvimento da história (CARVALHO; BRANDENBURG; FIALHO, 2019). Nessa perspectiva, o escrito biográfico hermenêutico vem à tona e ganha validade científica por conceber o sujeito no seu tempo e espaço, chamando atenção para as relações tecidas nas esferas pública e privada, facultando o desenvolvimento de uma biografia que analisa a individualidade e a coletividade indissociadas (DOSSE, 2015).

Lançar luz sobre a trajetória de indivíduos anônimos na teia social ou com parca visibilidade oportuniza tornar público nuances da história ainda veladas (FERRAROTI, 1998), uma vez que "a perspectiva de trabalhar com biografias e/ ou histórias de vida fornece subsídios para se entender o indivíduo em várias dimensões, bem como vislumbramos, também, os aspectos constituintes da sociedade de outrora [...]” (RODRIGUES, 2015, p.61). Nessa compreensão, ampara-se nos ensinamentos da micro história (LORIGA, 2011), que realça o indivíduo como produtor de conhecimento a partir da sua interação com o meio e com os seus pares, enfatizando grupos marginalizados da história, como mulheres e crianças, pois, a despeito do silenciamento desses grupos, suas trajetórias muito tem a corroborar para a escrita e para a compreensão da história (FIALHO; FREIRE, 2018). Destarte, a biografia de Minerva oportuniza analisar a historiografia dos eventos entremeados às suas experiências no ínterim do seu processo formativo e profissional, preservando tanto a memória individual quanto a social (MACHADO, 2006).

Objetivando biografar Minerva, com ênfase na sua trajetória profissional marcada pela luta por serviços assistenciais e caritativos e pelo atendimento especializado às pessoas com deficiência de Barbalha, a história oral foi eleita a metodologia adequada para o estudo em relato. Esta metodologia foi crucial para apreender as experiências por ela vivenciadas em meio às interações estabelecidas nos variados tempos e espaços, desde a oralidade de pessoas que conviveram com a biografada, especialmente, na Associação Pestalozzi de Barbalha. A história oral tornou factível o estudo da história contemporânea, pois “ “...] consiste na realização de entrevistas gravadas com indivíduos que participaram de, ou testemunharam acontecimentos e conjunturas do passado e do presente" (ALBERTI, 2005, p.155).

As memórias a respeito de Minerva, nos âmbitos público e privado, foram acessadas firmando a sua individualidade e, nesse viés, a memória se constituiu objeto da história oral, uma vez que esta serve-se daquela para reconstituir fatos e acontecimentos (THOMPSON, 2002). Partindo do entendimento de que a memória é seletiva e passa por filtros que envolvem o ato de lembrar, esquecer, significar e ressignificar (BOSI, 1993), a escrita biográfica em tela não buscou verdades absolutas; pelo contrário, admitiu que as particularidades de uma vida jamais serão apreendidas em sua totalidade.

A coleta dos dados foi realizada mediante entrevistas livres em história oral (MEIHY; HOLANDA, 2015) com 08 mulheres que conviveram com Minerva na Associação Pestalozzi de Barbalha. Todas assinaram o termo de consentimento livre e esclarecido no qual se explicava, dente outras coisas, o objetivo da pesquisa, forma de participação, ausência de benefícios, possíveis prejuízos, etc. As colaboradoras tiveram assegurado o anonimato, logo, serão referenciadas, nesse estudo, por Pestalozzi $1=\mathrm{P} 1$, Pestalozzi 2 = P2 e, assim, sucessivamente: P3, P4, P5, P6, P7 e P8.

As entrevistadas são todas do sexo feminino, cujas idades variam entre 35 e 72 anos de idade, ambas professoras com escolaridade superior e curso de pós-graduação lato sensu. As oralidades foram coletadas individualmente, em cada uma de suas residências, compreendendo o período de 3 a 5 de março de 2016, de acordo com agendamentos prévios realizados por telefone. As entrevistas foram registradas com apoio de gravador eletrônico, sendo, na sequência, transcritas, textualizadas e validadas mediante a técnica de estrutura geradora de discurso (FLICK, 2009), que possibilita a supressão, correção ou acréscimo de informações das colaboradoras, transformando a fonte oral em documento escrito autorizado.

\section{Resultados e Discussão}

Minerva nasceu no dia 2 de setembro de 1937 na cidade de Trujillo Alto, Porto Rico, estado livre associado dos Estados Unidos da América; segunda filha do casal Thomas Diaz Adorno e Juanita Ruiz Torres. Frequentou escola superior em Trujillo Alto e cursou Artes Liberais em Puerto Rico Junior College; estudou Secretariado na American University e Assistência Social na George Washington University, ambas instituições de cunho privado. Nota-se que pertenceu a uma família com considerável poder econômico, já que obteve progressão nos estudos, cursando mais de um curso superior em um tempo em que esse grau de instrução era inacessível à maioria das mulheres (GONDRA; SCHUELER, 2008).

Aos 25 anos de idade, enquanto se formava assistente social, foi uma das convidadas pelo Presidente Kennedy (1961-1963) a fazer parte do primeiro grupo de voluntários do Programa Corpos da Paz, que embarcaria para o Nordeste brasileiro em 1962 para desenvolver a juventude rural da Paraíba, cidade de serrarias e bananeiras. O Programa Corpos da Paz, lançado em 1961 pelo então presidente dos Estados Unidos, John Kennedy, encaminhou mais de seis mil jovens norte-americanos para o Brasil com o escopo de realizar trabalho humanitário na região Nordeste, que sofria com a miséria e suas consequências, como desnutrição e falta de 
atendimento médico (BERNARDES, 2007). De acordo com Bernardes (2007), a despeito do propósito divulgado pelo Programa Corpos da Paz, em meio aos atendimentos de pessoal americano aos menos favorecidos economicamente, o Governo dos Estados Unidos buscava firmar a sua posição como potência mundial e sujeitar países menos desenvolvidos, como o Brasil.

Concluído o voluntariado, já obtida a formação almejada na George Washington University, Minerva retornou à cidade de origem, onde trabalhou como auditiva no Departamento de Anomalias Orofaciais da Escola de Odontologia de Puerto Rico. Na mesma década, mais precisamente em 1964, voltou ao Brasil e para casar-se com o engenheiro agrônomo Antônio Inaldo de Sá Barreto, cidadão e político barbalhense com o qual havia se envolvido. Minerva tinha 27 anos quando casou, idade na qual, para a sociedade cearense do final do século XX, a mulher já poderia ser considerada "encalhada", sem idade adequada para contrair matrimônio, passando a sofrer preconceito e discriminação social (MAGALHÃES JUNIOR, 2003). Conquanto, Minerva destoou aos ditames impostos à mulher brasileira e constituiu sua família com quase trinta anos de idade, sendo mãe de três filhas: Dâmaris, Desirée e Thasis Cidália.

Dessa feita, pouco depois de fixar residência em Barbalha - município cearense localizado ao Sul do Estado, na Região Metropolitana do Cariri, a $504 \mathrm{~km}$ da capital, Fortaleza -, em decorrência da relação amorosa com Antônio Inaldo Barreto, Minerva ocupou a posição de primeira dama por seu esposo ter sido eleito prefeito por dois mandatos políticos (1976-1979; 1996-1999). Ela, que já era engajada em trabalhos voluntários de assistencialismo aos pauperizados brasileiros, promoveu uma revolução na estrutura de atendimento à população em situação de vulnerabilidade econômica, privilegiando-se do posto de primeira dama para promover ações caritativas e assistenciais para as quais a população jamais imaginava usufruir. Tamanha a negligência do Estado, justificada pela exiguidade dos recursos arrecadados, que implicava na oferta insignificante de insumos relacionados à educação e à saúde, fator que influía diretamente na qualidade de vida daqueles que habitavam as regiões interioranas (NOGUEIRA, 2011).

Destaca-se que, mesmo quando o esposo não ocupava o cargo de prefeito da cidade, Minerva continuava atuando nessa perspectiva, tendo ocupado a função de secretária do trabalho e ação social do município, quando se empenhou com maior afinco na luta pela melhoria de vida das pessoas pouco abastadas, possivelmente em decorrência dos ensinamentos que obteve em outrora, enquanto voluntária do programa norte-americano Corpos da Paz, que disseminava o sentimento de bondade e caridade para com os menos favorecidos economicamente (BERNARDES, 2007). Tais ações lhe ensejavam visibilidade social, que associadas ao prestígio dos cargos ocupados e ao seu empenho em ajudar os mais pobres, tornaram possível a constituição de uma imagem imaculada da biografada na região.
Interessa mencionar, que no final do século XX, no Brasil, não havia disseminação de uma percepção mais crítica das limitações do assistencialismo e caridade em detrimento da assistência social, especialmente nas cidades interioranas; pois as primeiras não possibilitam empoderamento para mudar conjunturas de vida enquanto a última, dissociada do favor, almeja a garantia de direitos constitucionais. A política voltada para cidadania, que se idealiza atualmente, implica em uma relação do Estado para com a sociedade baseada no direito efetivo e na participação social autônoma, em que o Estado se obriga não apenas a defender mas também a propiciar de fato os direitos legais (FIALHO, 2012), no entanto, não se pode desenvolver a anacronismo histórico, logo, sem essa percepção mais crítica, era compreensível que as pessoas do tempo de Minerva, que não possuíam suas necessidades básicas atendidas, desenvolvessem uma gratidão e admiração por uma mulher que lhes assistia em suas carências elementares não atendidas pelo poder público.

Em 1964, recém-chegada em Barbalha, Minerva se deparou com as necessidades e vulnerabilidades aparentes da população. Carência de toda natureza era visível na região do Cariri cearense ao primeiro contato - pobreza, miséria, exclusão, negação de direitos -, e os serviços públicos eram precários, especialmente no tocante à assistência social, saúde e educação (FIALHO, QUEIROZ, 2018). Sua residência, afastada do centro da cidade, facilitava o contato com aquela pobreza e abandono, sobretudo nos bairros e nos sítios nas imediações do seu domicílio, onde iniciou suas ações de assistencialismo.

Passados 12 anos, em 1976, o esposo Antônio Inaldo de Sá Barreto venceu as eleições municipais e se tonou prefeito de Barbalha. Nesse mesmo ano, Minerva Diaz, então primeira dama, iniciou o seu trabalho como gestora da Secretaria de Políticas Sociais dessa cidade, quando se aproximou ainda mais das periferias e, na tentativa de minimizar a vulnerabilidade, propôs iniciativas de promoção social, educacional, cultural, profissional e de saúde (LOPES; FIALHO; MACHADO, 2018). Uma de suas primeiras colaboradoras rememorou que, ao iniciar os trabalhos nessa secretaria, o foco era erradicar a desnutrição das crianças, percebida como um dos maiores problemas da região:

Naquela época havia uma necessidade muito grande, em razão dos altos índices de desnutrição e eu senti uma força muito grande da parte dela para transformar em trabalho que recuperasse essas crianças. [...]. Tudo o que eu aprendi em relação ao trabalho social foi com Dona Minerva [...]. Eu percebo que o trabalho social implantado aqui na cidade de Barbalha é algo que ficará para sempre (P6, 05/01/2016).

O empenho no trabalho social e a penetração no cenário internacional contribuíram para que Minerva compreendesse que as condições de vida no Nordeste brasileiro eram inaceitáveis, especialmente no que dizia respeito a fome e desnutrição infantil. Por ter cumprido atividades voluntárias em programa financiado pelos Estados Unidos, quando teve 
experiência na assistência social aos paraibanos, ganhou experiência no trato com a população carente e já conhecia as principais demandas que assolavam o nordeste brasileiro. Essa experiência, mais tarde, foi ressignificada na condição de primeira dama em Barbalha, e suas articulações políticas possibilitaram agilizar e tensionar os fluxos de projetos com foco na melhoria da vida dos cidadãos pauperizados. Posto que a estrutura política, econômica e administrativa de Barbalha se assemelhava a de outras cidades do Nordeste, tal como na Paraíba e, na condição de primeira dama, pode interferir na máquina pública e continuar o seu trabalho na assistência social, com mais afinco, dispondo de mais recursos para tal.

Em 1980, a partir de sua iniciativa, foi criada a Sociedade de Apoio à Família (SOAFA), com vistas a atender às necessidades das famílias extremamente pobres da região mais central de Barbalha. Integravam essa iniciativa os seguintes projetos: o plantio de hortaliças, como forma de suprir as necessidades nutricionais e fomentar a geração de renda; o Projeto Cabra-Leiteira, por meio do qual as famílias recebiam uma cabra para criar e gerar leite para as crianças; o Projeto Banco de Sementes, que visava a distribuição de sementes para agricultores da região conseguirem manter seu roçado; e ainda buscou garantir moradia por meio da doação de materiais para construção de casas em regime de mutirão. A SOAFA também contava com uma creche que atendia crianças com idades entre 2 e 5 anos, sendo aquelas desnutridas o foco principal.

Como a década de 80 antecede o entendimento da Educação Infantil como fase da escolarização que demanda de particularidades para o efetivo desenvolvimento da criança, (SARMENTO, 2008), compreensão essa disseminada mais tarde pela Lei de Diretrizes e Bases da Educação Nacional (BRASIL, 1996), a creche do SOAFA objetivava assistir às crianças mais carentes cujas famílias necessitavam trabalhar $\mathrm{e}$ não tinham com quem deixar os filhos. Mesmo fundamentada no assistencialismo e não centrada nos processos de educação e desenvolvimento das crianças, pode-se considerar que se tratava de uma iniciativa valiosa, já que sequer existia creche subsidiada pelo Estado no período em tela (SAVIANI, 2011).

Cinco anos mais tarde, em 1985, Minerva esteve à frente da fundação da Sociedade de Educação e Saúde da Família (SOBEF), iniciativa que englobava todos os programas que integravam a SOAFA, mas com foco não mais na população central, mas nos residentes de sítios e povoados da zona rural de Barbalha. Além da plantação de hortaliças, do projeto Cabra-leiteira e do Banco de Sementes, a SOBEF investiu na construção de engenhos de mel e rapadura, tanto para o consumo quanto para gerar renda para aquela população. De natureza filantrópica, com patrocínio da sociedade civil e do Estado, a SOBEF, até os dias atuais (ano de 2020), continua a desenvolver atividades culturais e ações para garantir os direitos de crianças e de adolescentes em situação de privação, exclusão e vulnerabilidade social.
A partir dos desmembramentos da SOAFA e da SOBEF, que tornava clara as áreas mais necessitadas de investimento, ainda em 1985, Minerva criou a Sociedade de Educação e Saúde à Família (SESFA). Essa, por sua vez, se voltou para crianças, adolescentes e jovens com idades entre 0 e 24 anos, em condição de vulnerabilidade social e expostos à violência nas periferias, bem como para suas famílias, com o objetivo de promover a autonomia por meio de programações culturais para o desenvolvimento sociocultural e psicossocial dos assistidos.

Por meio de tais iniciativas, ainda em atividade em Barbalha, Minerva deu início à Legião Brasileira de Assistência (LBA) em sua cidade. Essa organização, extinta em 1990, previa o desenvolvimento de ações sociais por iniciativa das primeiras-damas, que recebiam apoio da União, mesmo que insuficientes. Uma das entrevistadas, ao narrar sobre o momento em que Minerva levou a LBA à Barbalha, esclareceu que, por falta de espaço, todos os projetos funcionavam no mesmo compartimento:

Ela fez uma grande revolução na Barbalha. Quando começou como primeira dama tratou logo de trazer a LBA - Legião Brasileira de Assistência. Até então nenhuma primeira dama tinha se esforçado para trazer essa ação [...]. Todo o trabalho começou sem muita condição, funcionava no mesmo local [...] (P2, 05/01/2016).

Apesar das dificuldades, foram sendo implantadas ações de maneira improvisada e insipiente que articulavam a assistência e a promoção social, pois, ao mesmo tempo em que se enxergava a necessidade de resolver os problemas imediatos da população, como a fome e a falta de moradia, também eram implementadas iniciativas que proporcionavam frutos a longo prazo, como o apoio e o incentivo às atividades do comércio familiar por meio da SESFA e da SOBEF, que envolvia formação para implantação de pequenos negócios. Avaliando as ações de Minerva Diaz, P4 (04/01/2016) avalia que "o trabalho dela não era de assistencialismo, e sim de promoção; ela não dava apenas o pão. Ela dava o trabalho para você trabalhar e ter sua vida com dignidade $[. .$.$] ".$

As constantes peregrinações em meio aos espaços periféricos, que se iniciaram assim que chegou à Barbalha, em 1964, a fez tomar conhecimento não somente acerca das vulnerabilidades, mas também identificar quais áreas demandavam de atendimento prioritário, a exemplo do público infantil, que apresentava maior urgência. Ante a indignação com esse contexto, Minerva estabeleceu articulações com instituições nacionais e internacionais e trouxe para Barbalha a prática do apadrinhamento, por meio do qual o padrinho ou a madrinha fazia doações mensais para o seu "afilhado" com vistas à garantia de serviços de saúde, educação, nutrição e outros relacionados ao seu bem-estar. Esse projeto se tornou viável, especialmente, por meio do Fundo Cristão para Crianças, organização brasileira fundada em 1966 para a promoção de crianças, jovens e adolescentes de famílias em situação de risco social, com a elaboração e monitoramento 
de projetos e programas, sendo o apadrinhamento um deles.

Dentre grupo apontado com maior índice de vulnerabilidade social, Minerva resolveu se voltar um subgrupo específico: crianças com deficiência. Essas, por sua vez, necessitariam de atendimentos específicos, serviços não custeados e ofertados pelo poder público, que nesse período era alheio às famílias das pessoas com deficiência (RODRIGUES; GAI, 2016).

Ela descobriu [...] e começou a fazer um trabalho voltado para atender essas pessoas. Investiu toda a sua vida, tudo o que sabia, o que aprendeu de suas experiências nos EUA e no Brasil, para que trabalhássemos com essas crianças. Então o trabalho foi sendo espalhado por toda a cidade e apareceram muitas pessoas necessitadas (P7, 03/01/2016).

Dessa feita, o serviço de assistência, que fez avultar um contingente de pessoas até então em condição de anonimato na teia social, ganhou um novo cenário. Agora, foram implantados serviços peculiares às necessidades da criança com deficiência, que passou a funcionar de modo concomitante e complementar aos atendimentos já em exercício. A narrativa de P8 (05/01/2016) assinala que "tudo foi feito em benefício das crianças. Dona Minerva dizia que tudo era para que as crianças tivessem uma vida melhor, mais segurança [...]”. Seguindo esse pensamento, uma das suas principais metas foi criar uma instituição própria para essa finalidade; foi quando começou a ser idealizada a Associação Pestalozzi.

A Associação Pestalozzi do município de Barbalha é uma instituição sem fins lucrativos, que foi criada em 12 de outubro de 1977, tendo Minerva como idealizadora. O objetivo foi ofertar serviços assistenciais, em Barbalha e adjacências, que propiciassem o desenvolvimento de crianças e adolescentes carentes com deficiência e às suas famílias, pois até então a cidade não contava com nenhuma entidade, seja pública ou privada, com vistas a essa finalidade.

Criar uma organização voltada para assistir os deficientes foi não apenas uma das metas de Minerva, mas também projeto de campanha eleitoral na qual o esposo foi eleito prefeito, em 1976. Como informa uma das entrevistadas:

Quando Dr. Inaldo foi eleito, ela começou esse trabalho social [...] porque se comoveu com a situação que encontrou na época da campanha, quando visitava as casas e encontrava as crianças amarradas, presas, isoladas, jogadas de todo jeito. Os pais tinham vergonha. Eram crianças com deficiência e outras completamente atrasadas em função da fome e abandono (P4, 04/01/2016).

Até esse período era inexistente a disseminação de produção de conhecimento acerca das pessoas com deficiência em Barbalha e, por conseguinte, também não havia os serviços especializados para prover atendimentos especializado, seja de cunho educativo ou no âmbito da saúde, que proporcionassem o desenvolvimento das crianças deficientes (MARTÍN; PÉREZ; ESTEBAN, 2017). Dessa maneira, as crianças acometidas com deficiência intelectual eram excluídas do convívio social, sendo motivo de vergonha para os pais e demais familiares, fator que dificultou o trabalho realizado pela Associação Pestalozzi em Barbalha.

Ainda me lembro daquele tempo bem difícil quando nós começamos. Não tínhamos muita noção do que fazer, porque as crianças eram escondidas por suas famílias, representava uma vergonha ter um filho com deficiência ou limitação de qualquer natureza. Eu lembro que a gente saía visitando as casas para localizar as crianças e era motivo de gozação, as pessoas riam, zombavam daquelas crianças de uma forma perversa [...]. Todas nós sabemos das dificuldades do seu início, do quanto a discriminação comprometeu as boas intenções (P5, 05/01/2016).

Esse relato retrata uma época na qual a segregação do deficiente era naturalizada e os comentários preconceituosos não eram entendidos como discriminatórios. Um tempo em que o sistema educacional excluía quem fosse considerado fora dos padrões de normalidade e o Estado se eximia do seu dever de promover a educação e o desenvolvimento de todos indistintamente, independente da condição social, intelectual e econômica (FREITAS; BICCAS, 2009). Na contramão, Minerva foi pioneira na sua região a se empenhar na melhoria de condições de vida para as crianças deficientes, pois possuía uma visão diferenciada graças a sua formação nos EUA.

Minerva não era brasileira, ela era de Porto Rico e, por isso, tinha uma visão muito diferente. Ela veio de um país muito adiantado, estudou nos EUA [...]. Foi muito difícil o início de todo seu trabalho. Foi uma luta grande, sem dinheiro, mas ela era uma mulher de garra e, fundar o Pestalozzi foi, ao mesmo tempo um desafio e uma grande conquista, para si mesma e para o povo de Barbalha (P2, 05/01/2016).

Para a entrevistada P2, o pioneirismo e protagonismo de Minerva na luta pela inclusão dos deficientes são decorrentes da formação nos EUA e das experiências que teve fora do Brasil, que permitiram capital cultural $^{2}$ e informacional diferenciado, auxiliando-a tanto para compreender a deficiência sem preconceito como fomentando o engajamento pela causa das pessoas com deficiência com vistas a melhorar a situação desumana de vida que levavam em Barbalha nas últimas décadas do século XX.

Manter a Associação Pestalozzi em funcionamento implicava encarar desafios permanentes. Além das restrições de cunho financeiro, Minerva se deparava com a ausência de profissionais com formação adequada para atuar junto aos deficientes. Por isso, era exigente quanto à escolarização das funcionárias da Associação Pestalozzi, que deveria ser em nível de pós-graduação, conforme relato:

Ela tinha um amor inexplicável pelo trabalho e colocou todas nós para estudar. Então fomos estudar, primeiro fazendo uma faculdade; depois, cursos de especialização e outros treinamentos, de acordo com os atendimentos clínico, pedagógico, profissionalizante e de inclusão social [...]. Recebemos sempre o melhor exemplo dela - apoio, incentivo, motivação (P4, 05/01/2016).

2 Para Bourdieu (2003), capital cultural são os insumos que o indivíduo possui e que passam a fazer parte de si, como um habitus que norteia as condutas, as percepções e os valores que regem a vida social e que perpassam as experiências vivenciadas nos aspectos individual e coletivo. 
A despeito da preocupação demonstrada por Minerva com a formação em nível de especialização para quem tivesse interesse em continuar atuando na Associação Pestalozzi, decorria do fato de os cursos de licenciaturas ainda não contemplarem em seus currículos a educação para pessoa com deficiência a contento (VIEIRA; FARIA, 2019), o que acarretava em uma formação insuficiente para lidar com as especificidades que chegavam no dia a dia do Instituto Pestalozzi. Conforme enfatizado por uma das entrevistadas, “[...] as licenciaturas não abordavam a educação especial. Os professores não falavam a respeito das deficiências, até porque os formadores desconheciam (VASCONCELOS; FIALHO; LOPES, 2018). O trabalho na região era muito novo, até no Ceará" (P5, 05/01/2016).

Minerva incentivava a formação continuada e providenciava cursos complementares e participação em eventos com vista a atualização e aperfeiçoamento à formação inicial para as suas companheiras de trabalho.

Tudo era muito novo. Tivemos que estudar muito para aprender sobre aquela pedagogia de atendimento, assistência, educação e formação profissional de crianças e adolescentes deficientes. Esse trabalho foi pioneiro na Barbalha, então tivemos que estudar muito, fomos para encontros e congressos sempre acompanhadas de Dona Minerva. Ela tinha uma enorme vontade de aprender [...] (P1, 03/01/2016).

Frequentar congressos, palestras e cursos de curta duração era uma necessidade porque, àquela época, as licenciaturas e o Curso Normal ainda eram discutidos pelas políticas de formação de professores e havia indefinição acerca das peculiaridades que deveriam compor o processo formativo para o magistério, inclusive no que concerne ao desenvolvimento de crianças com deficiência (MARTÍN; PÉREZ; ESTEBAN, 2017). Somente ao final do século passado as políticas de educação foram reelaboradas, acompanhando as demandas socioeconômicas e políticas e, nesse contexto, ao definir estratégias pedagógicas para a educação formal, o atendimento às pessoas com deficiência também foi realçado, quando o Ministério da Educação compreendeu que seria impossível garantir o desenvolvimento de todos os estudantes, caso a educação não fosse diferenciada e os professores contassem com formações continuadas ao longo da prática docente (FONSECA; COLARES; COSTA, 2019).

Os investimentos públicos para oferta e custeio de formação específica para trabalhar com as pessoas com deficiência eram precários, da mesma forma como ocorria com o fomento financeiro às instituições que assistiam às crianças necessitadas de atendimento especializado (MARTÍN; PEREZ; ESTEBAN, 2017). Com efeito, havia a transferência de responsabilidade do Estado para a gestora da Associação Pestalozzi de Barbalha, Minerva. Pois, mesmo quando, ao final do século XX, tiveram início ações com vistas à formação continuada de profissionais atuantes em instituições voltadas para o atendimento de pessoas com deficiência (SOUSA; NASCIMENTO, 2018), os recursos ficaram concentrado em outras regiões do país, conforme denúncia P5:

[...] as primeiras experiências de formação foram nos estados do Sul e Sudeste do Brasil. Depois tivemos alguns cursos em Fortaleza. Tudo muito difícil, não havia recursos públicos, dependíamos de bolsas do Governo Federal ou Estadual, quando aparecia, porque normalmente ficava todo o recurso nas regiões desenvolvidas. O Nordeste, como sempre, era esquecido (P5, 05/01/2016).

Dessa maneira, ante a insuficiência de investimento público, o empenho de Minerva foi crucial para promover o aperfeiçoamento das profissionais que atuavam na Associação Pestalozzi de Barbalha, que galgaram incentivo da mentora da instituição, conforme a narrativa de P1: "Tudo o que eu sei hoje é porque ela sempre se preocupou em favorecer a formação para todas as pessoas que trabalhavam com ela. Ela lutava muito [...]" (P1, 05/01/2016). Outra entrevistada ressaltou o exemplo de Minerva, que também era aspecto formativo para quem com ela convivia: “A minha formação profissional tem mais Minerva do que qualquer outro educador que eu tenha estudado na vida" (P1, 04/01/2016).

Em decorrência de tais feitos, Minerva conquistou admiração de suas colegas de profissão e visibilidade social tanto na cidade onde viveu a maior parte da vida - Barbalha, como em âmbito nacional, já que foi convidada por José Sarney, quando presidente da República, a se dirigir à Brasília para tratar de temas relacionados à inclusão escolar de pessoas com deficiência. Internacionalmente, foi eleita pelo ex-presidente Kennedy como uma das melhores voluntárias do Programa Corpo da Paz, e foi convidada pelo também expresidente americano Lyndon Jonhson a auxiliar na escrita de um documento sobre os passos do voluntariado no Brasil. No Ceará, além do protagonismo em Barbalha, apoiou e incentivou a criação dos Institutos Pestalozzi de Missão Velha, Milagres e Campos Sales, outras cidades da região Sul do Estado. Minerva faleceu em 3 de agosto de 2010, encerrando suas atividades na causa das pessoas com deficiência; no entanto, a associação continua em funcionamento gerida por seus familiares.

\section{Conclusão}

Partiu-se da inquietação acerca de como uma mulher de nacionalidade americana, ao chegar à Barbalha, cidade nordestina marcada pela precariedade de recursos públicos, conseguiu se tornar referência no trabalho com a assistência social e fundar a Associação Pestalozzi - primeira instituição da região a atender pessoas com deficiência. Para responder a essa problemática, objetivou-se biografar Minerva Diaz de Sá Barreto com ênfase no seu envolvimento com as práticas caritativas e de assistência social que fomentaram atendimento às pessoas com deficiência da cidade de Barbalha-CE (19642010)

O escopo foi assentado em uma pesquisa no campo da história da educação, de natureza qualitativa, amparada metodologicamente na história oral, por meio da qual 
foi possível ter acesso às oralidades de 08 pessoas que conviveram com Minerva no período em que ela fundou e geriu a Associação Pestalozzi de Barbalha. As entrevistas, livres e sem roteiro, possibilitaram constituir uma narrativa biográfica de Minerva que considerou aspectos familiares, educativos, econômicos e profissionais.

Os resultados inferiram que Minerva foi uma mulher de nacionalidade americana, com boas condições econômicas, que obteve toda sua formação educação em instituições privadas dos Estados Unidos. Ela teve a oportunidade de conhecer o nordeste brasileiro por intermédio da participação em um grupo de voluntários do Programa Corpos da Paz, lançado em 1961, pelo então presidente dos Estados Unidos, John Kennedy. Nesta oportunidade conheceu a realidade nordestina e se sensibilizou com as precárias condições de vida da região. Mais tarde, após formar-se Assistente Social na George Washington University, fixa residência permanente no interior do Ceará ao casar com um cidadão do município de Barbalha. Adquiriu cidadania brasileira em decorrência do seu matrimônio, teve três filhas, e durante toda sua estadia no Brasil atuou prestando assistência aos menos favorecidos economicamente.

Diferente da maior parte das moças de Barbalha da década de 1930, que possuíam baixa escolarização e eram educadas para contrair um bom casamento e obter escolarização em nível elementar, Minerva logrou de trajetória educativa diferenciada e requintada nos EUA, adquirindo capital cultural que destoava à educação feminina fomentada em Barbalha. Inclusive no que concerne a compreensão do desenvolvimento das pessoas com deficiência, foco sua atuação profissional, encaradas como uma vergonha pelas famílias brabalhenses e acolhidas desprovidas de preconceitos por Minerva.

$\mathrm{Na}$ região do Cariri, tornou-se primeira-dama por quatro anos, pois seu esposo assumiu dois mandatos políticos como prefeito da cidade. Essa condição privilegiada impulsionou o trabalho social destinado ao público menos favorecido economicamente, que sofria com privações de direitos básicos garantidos constitucionalmente e negligenciados pelo Estado - saúde, educação, moradia, alimentação, dentre outros. Com vistas a proporcionar melhores condições de vida e de desenvolvimento para essa parcela da população, desenvolveu projetos - Plantio de hortaliças, Projeto Cabra-Leiteira, Projeto Banco de Sementes, etc.- e fundou organizações caritativas que assistiam aos mais necessitados. Chamou-lhe atenção um subgrupo até então discriminado e desconsiderado na teia social - as crianças com deficiência, para quem destinou maior parte de suas atenções, inclusive fundando a Associação Pestalozzi de Barbalha.

Minerva foi pioneira na luta por condições específicas de atendimento às pessoas com deficiência em Barbalha, e sua atuação à frente da Associação Pestalozzi foi marcada por percalços: limitação de recursos financeiros e falta de profissionais qualificados para o atendimento às crianças deficientes. Destarte, conseguiu manter a referida organização em exercício, proporcionando atendimento específico e ainda conseguiu prover instrução para os profissionais ali atuantes, incentivando e intermediando oportunidades de formação inicial e continuada na área da inclusão de pessoas com deficiência, temática pouco discutido à época.

Conclui-se que o reconhecimento social e a atuação profissional de Minerva, junto às crianças com deficiência de Barbalha e adjacências, foram possíveis graças ao capital cultural adquirido fora do Brasil, a sua sensibilização pessoal a esta causa, e a condição de esposa do prefeito da cidade, pois esta última permitiu galgar recursos e contatos para fundar e manter a Associação Pestalozzi de Barbalha. O estudo centrado na biografia de Minerva Diaz de Sá Barreto foi crucial para ampliar o entendimento dos aspectos educacionais e socioculturais que perpassam a história da educação inclusiva em Barbalha, pois sua vida está interrelacionada indissociavelmente, tanto no âmbito pessoal como profissional, a história do atendimento às pessoas com deficiência.

Uma biografia possui a limitação de não ser passível de generalizações, todavia, em cidade que sequer há narrativa histórica constituída acerca do atendimento e educação das pessoas com deficiência, esse tipo de estudo ganha valor por contribuir para ampliar a compreensão do contexto educacional e social que relegava os deficientes ao esquecimento e reclusão, bem como seu ingresso na sociedade como cidadãos de direitos. Traz reflexões que podem contribuir para outras pesquisas acerca da história da educação de Barbalha, da história pessoa com deficiência e da história de instituições.

\section{Referências}

ABU-EL-HAJ, M.F.; FIALHO, L.M.F. Formação docente e práticas pedagógicas multiculturais críticas. Revista Educação em Questão, v.57, p.1-27, 2019. doi: https://doi.org/10.21680/1981$1802.2019 \mathrm{v} 57 \mathrm{n} 53$ ID 17109

ALBERTI, V. Histórias dentro da história. In: PINSKY, C. (Org.) Fontes históricas. São Paulo, Contexto, 2005. p.155-202.

ARAÚJO, H.L.M.R. A tradicional Escola Normal Rural Cearense chega ao Bairro de Fátima Formação das primeiras professoras primárias (1958-1950). Fortaleza: UFC, 2015.

BERNARDES, B.M. Notas sobre a formação social no Nordeste. Lua Nova, v.71, p.41-79, 2007. doi: https://doi.org/10.1590/ S0102-64452007000200003

BOURDIEU, P. Os três estados do capital cultural. In: NOGUEIRA, M. A; CATANI, A. (Org.). Escritos de Educação. Petrópolis: Vozes, 2003. p.3-79.

BOSI, E. A pesquisa em memória social. Psicologia USP, v.4, n.12, p.277-284, 1993.

BRASIL. Ministério da Educação. Lei $n^{\circ}$ 9.394/96, de 20 de dezembro de 1996. Lei de Diretrizes e Bases da Educação Nacional. Brasília: MEC, 1996.

BURKE, P. O que é história cultural? Rio de Janeiro: Zahar, 2008.

CARVALHO, S.O.C.; BRANDENBURG, C.; FIALHO, L.F. História cultural e micro-história: reflexões preliminares. In: RIBEIRO, L.T.F.; SILVA, S.M.A.; CASTRO, F.M.F.M. 
(ORGS Org.). Debates em história da educação e formação de professores: perspectivas da educação contemporânea. Fortaleza: EdUECE, 2019, p.25-40.

DOSSE, F. O desafio biográfico: escrever uma vida. São Paulo: Universidade de São Paulo, 2015.

FERRAROTI, F. Sobre a autonomia do método biográfico. In: NÓVOA, A; FINGER, M (Org.). O método (auto)biográfico e a formação. Lisboa: MS/DRHS/CFAP, 1988. p.17-34.

FIALHO, L.M.F. O Ensino Médio ministrado no Centro Educacional Patativa do Assaré. Holos, v.2, p.184-192, 2012. doi: https://doi.org/10.15628/holos.2012.870

FIALHO, L.M.F.; FREIRE, V.C.F. Educação formativa de uma líder política cearense: Maria Luíza Fontenele (1950-1965). Cad. Hist. Educ., v.17, n.2, p.343-364, 2018. doi: https://doi. org/10.14393/che-v17n2-2018-5

FIALHO, L.M.F.; QUEIROZ, Z.F. Maria Neli Sobreira: história e memória da educação em Juazeiro do Norte. Educar em Revista, v. 34, p. 67-84, 2018. doi: https://doi.org/10.1590/01044060.58763 .

FLICK, U. Introdução à pesquisa qualitativa. Porto Alegre: Artmed, 2009.

FREITAS, M.C.; BICCAS, M.S. História Social da Educação no Brasil (1926-1996). São Paulo, Cortez, 2009.

FONSECA, A.; COLARES, A.; COSTA, S. Educação infantil: história, formação e desafios. Educação \& Formação, v. 4, n. 12, 2019. doi: https://doi.org/10.25053/redufor.v4i12.1270

GONDRA, J.G.; SCHUELER, A. Educação, poder e Sociedade no Império Brasileiro. São Paulo: Cortez, 2008.

MACHADO, C.J.S. Mulher e Educação: histórias, práticas e representações. João Pessoa: UFPB, 2006.

MAGALHÃES JUNIOR, A.G. Vigilância, transgressão e "punição": memórias de ex-alunas de escolas católicas de formação de educadoras (1964-1969). 2003. 201f. Tese (Doutorado em Educação) - Programa de Pós-Graduação em Educação Brasileira, Universidade Federal do Ceará, Fortaleza, 2003.

MEIHY, J.C.S.B.; HOLANDA F. História oral: como fazer como pensar. São Paulo: Contexto, 2015.

LEVI, G. Usos da biografia. In: AMADO, J.; FERREIRA, M.M. Usos \& abusos da História Oral. Rio de Janeiro: editora FGV, 2016, p.167-182.
LOPES, T.M.R.; FIALHO, L.M.F.; MACHADO, C.J.S. Mulheres educadoras do Cariri cearense no fomento à inclusão (1970-1990). Linguagens, Educação e Sociedade, v.23, p.240261, 2018.

LORIGA, S. O pequeno $x$ : da biografia à história. Belo Horizonte: Autêntica, 2011.

MARTÍN, L.; PÉREZ, M.C.; ESTEBAN, M.C. La formación inicial de profesores en matemáticas y su influencia en la mejora educativa de alumnado con necesidades específicas. Educação \& Formação, v.2, n.5, p.03-19, 2017. doi: https://doi.org/10.25053/ edufor.v2i5.2173

NOGUEIRA, D.L. Amália Xavier e a Escola Normal Rural de Juazeiro do Norte: registros sob a constituição de uma cultura docente para a educação no campo. Fortaleza: IMEPH, 2011.

PERROT, M. Os excluídos da história: operários, mulheres e prisioneiros. Rio de Janeiro: Paz e Terra, 2017.

RODRIGUES, E.; GAI, D. Atendimento educacional especializado e atelier pedagógico (entre deficiência potencial e arte potencial). Educação \& Formação, v.1, n.3, p.125-139, 2016. doi: ttps://doi.org/10.25053/edufor.v1i3.1620

RODRIGUES, R.M. Biografia e Gênero. In: FILAHO, L.M.F.; VASCONCELOS, J.G.; SANTANA, R.J (Өrgs Org.). Biografia de mulheres. Fortaleza: EdUece, 2015, p. 54-70.

SARMENTO, M.J. Sociologia da infância: definindo conceitos, delimitando o campo. In: PINTO, M; SARMENTO, M.J. As crianças, conceitos e identidades. Braga: Universidade do Minho, 1997. p.9-30.

SAVIANI, D. História das ideias pedagógicas no Brasil. Campinas: Autores Associados, 2011.

SOUSA, N.M.; NASCIMENTO, D. A inclusão escolar e o aluno com Síndrome de Down. Educação \& Formação, v.3, n.9, p.121140, 2018. doi: https://doi.org/10.25053/redufor.v3i9.859

THOMPSON, P. A voz do passado: história oral. Rio de Janeiro: Paz e Terra, 2002.

VASCONCELOS, J.G.; FIALHO, L.M.F.; LOPES, T.M.R. Educação e liberdade em Rousseau. Educação \& Formação, v.3, p.210-223, 2018. doi: https://doi.org/10.25053/redufor.v3i8.278

VIEIRA, C; FARIA, M.N. Formação de professores nos debates da i conferência nacional de educação (ICNE - 1927). Educação \& Formação, v.4, n.10, p.95-111, 2019. doi: https:// doi.org/10.25053/redufor.v4i10.391. 